\title{
Yoksulluk ve Gelir Dağılımı Eşitsizliği: OECD ve AB Ülkeleri Panel Veri
} Analizi

\author{
Poverty\&Inequality: Panel Data Analysis for OECD and EU \\ Berna BALCI İZGi* \\ Ebubekir ALYU *
}

$\ddot{\mathrm{O} z}$

Yoksulluk, sosyal ve ekonomik olarak olumsuz etkileri olan önemli bir sorundur. Geleceği planlarken ülkelerin iktisadi kalkınmalarında dikkate almaları gereken çok çeşitli parametrelerden biri yoksulluk diğeri de gelir dağılımındaki eşitliktir. Avrupa Birliği’'nin 2004 ve 2007 yıllarındaki genişlemesinden sonra bölgesel ayrışmaları azaltmak temel bir hedef haline gelmiştir. Genel kabul gören bir görüş, AB 15 ülkesi için gelir rraksamasının daraldığı yönündedir. Kişi başı GSYİH'sı yüksek olan bir bölge yüksek oranda yoksulluk çekiyor olmakla birlikte düşük GSYİH'sı olan bir ülkenin bazı alanlarında yüksek zenginlik görülebilmektedir. Ortalama gelir düzeyi düşük olan bir bölgeye ayrılan kaynaklar azınlıkta kalan üst orta gelir grubu için iyi ödenekli yeni işler getirirken bir yandan da daha yüksek gelir eşitsizliği ile sonuçlanmaktadır. İktisat yazınında yoksulluk ve gelir dağılımı eşitsizliği değişkenleri genellikle ekonomik büyüme değişkeni ile birlikte analiz edilmektedir.

Anahtar Kelime: Yoksulluk, gelir dağılımı, panel veri analizi.

\begin{abstract}
Poverty is a crucial problem socio-economically. Planning thefutureone of theparameters is poverty and the other one is income equality for the countries in economic development. After the expansion of 2004 and 2007 decreasing regional divergences has become a fundamental purpose for European Union. It is claimed that the new 12 members whose per capitagdp falls below the half of the previous members areseen as a threat. A generally accepted view accepts then orrowing of income divergence for EU 15. A high rate of poverty could be seen in a high per capitain come region while the opposite is alsotrue. The financial resources may bring new good pay jobs on the otherhand a higher in come inequality may be a result. This study aim stoanalysethe OECD-35 EU-26 in a panel data environment. Fixed effect and random effect tests and Hausman test was applied. While Breusch-Pagan test suggests the pooledols. According to the findings, as total poverty thres hold increases inequality increases as well.
\end{abstract}

Keywords:Poverty, incomedistribution, panel data analysis.

\section{Giriş}

Gelişmiş ve gelişmekte olan ülkeler iktisadi kalkınma açısından karşılaştırıldığında önemli makroekonomik göstergelerden biri gelir dağılımı ve yoksulluktur. Gelirin paylaşımındaki adalet ve yanı sıra ortalama gelirin \%60 altında yaşam standardına sahip olanları gösteren yoksulluğun azaltılması herkesin görüş birliğine vardığı bir konudur. Yoksulluğun azaltılması, ülkelerin gündemini oluşturan kalkınma stratejilerinin temel konu başlıklarından biridir. Birbirini tamamlayan iki değişken olan gelir dağılımı eşitliği ve yoksulluk kavramlarını tanım olarak incelemeye başlamak adet olmuştur.

Gelir dağılımı ve yoksulluk arasında sıkı bir ilişki vardır. Belirli bir gelir düzeyinde gelir dağılımı eşitsizliği ne kadar yüksek ise yoksulluk oranı da o denli yüksektir.Gelir dağılımı; belirli bir dönemdeki toplam gelirin elde edilmesine katkıda bulunanların bu gelirden aldıkları paylara verilen addır. Gelir dağılımında eşitsizliğin artması, geçim sıkıntısına yol açar, ekonomi sağlıklı ve istikrarlı bir şekilde büyüyemez.Yoksulluk;Eurostat'ın tanımına göre bir ülkenin yoksulluk oranı gelirleri ortalama mili gelirin $\% 60$ altına düşen hanehalkının yüzdesini ifade etmektedir. Mutlak yoksulluk, hanehalkı veya kişilerin ihtiyaç duydukları asgari gelir ve harcama düzeyidir.

Ülkelerarası karşılaştırmaların yapılması amacıyla kullanılır. Nisbi yoksulluk ise farklı grupların sahip olduğu mutlak gelir seviyelerinden çok gelir ve refahın dağılımındaki

\footnotetext{
* Doç.Dr.,Gaziantep Üniversitesi,İ̈BF,İktisat Bölümü, izgi@gantep.edu.tr

** Öğr.Gör., Çukurova Üniversitesi,Ceyhan MYO, ealyu@cu.edu.tr.
} 
farklılıklara odaklanır. Nisbi yoksulluk, yoksul hanehalkı ile o toplumda yaşayan ve mevcut şartlara göre ortalama bir gelire sahip olan hanehalkı arasındaki gelir kaynaklarına sahip olma arasındaki farktır (Karluk, 2009,s.102).

Kalkınma konusundaki temel tartışma konularından bir tanesi, temel hedefin ekonomik büyüme mi yoksa yoksulluk ve/veya gelir eşitsizliği mi olması gerektiği üzerinedir (Bourguignon,2004) bu soruya yanıt olarak mutlak yoksulluğun her formunun azaltılmasının anlamlı bir hedef olacağını belirtmektedir. Gelir dağılımı politikalarını belirlerken ülkespesifik karşılaştırmalara ihtiyaç vardır. Yoksulluk eşiği konusu parasal ve parasal olmayan unsurları içerdiği için çok boyutlu bir konudur. Örneğin $A B$, yoksulluk eşiğini ortalama gelirinin \%50’sinin altında olan üye ülkeleri fakir grubuna almaktadır.

Yoksulluğun azaltılmasında ekonomik büyümenin temel olduğu konusunda ekonomistler arasında çok az görüş ayrılığı vardır (Bkz.Dollar ve Kray,2001;Ravallion,2002, Bourguignon,2003). Birçok kanıt göstermektedir ki gelir dağılımının bozulması yoksulluğu arttırmaktadır. Yoksulluk, hanehalkı araştırmalarına göre genellkle mutlak yoksulluk endeksi ile ölçülmekte ve günde 1 doların altı yoksulluk sınırı olarak alınmaktadır. Eşitsizlik toplam nüfusun içindeki nisbi gelir farklılıkları olarak alınmaktadır. Büyüme ise ortalama refah seviyesindeki yüzde değişim olarak alınmaktadır. Şekil 1'e göre gelir dağılımındaki değişimin etkisi ikiye ayrılmaktadır. Büyüme etkisi bütün gelir düzeyleri için oransal değişime denir. Dağılım etkisi ise, ortalamadan bağımsız olarak nisbi gelir dağılımındaki değişime verilen addir (Bourguignon,2004).

Şekil 1:Yoksulluk-büyüme-eşitsizlik üçgeni

Mutlak yoksulluk ve

yoksulluk azalması
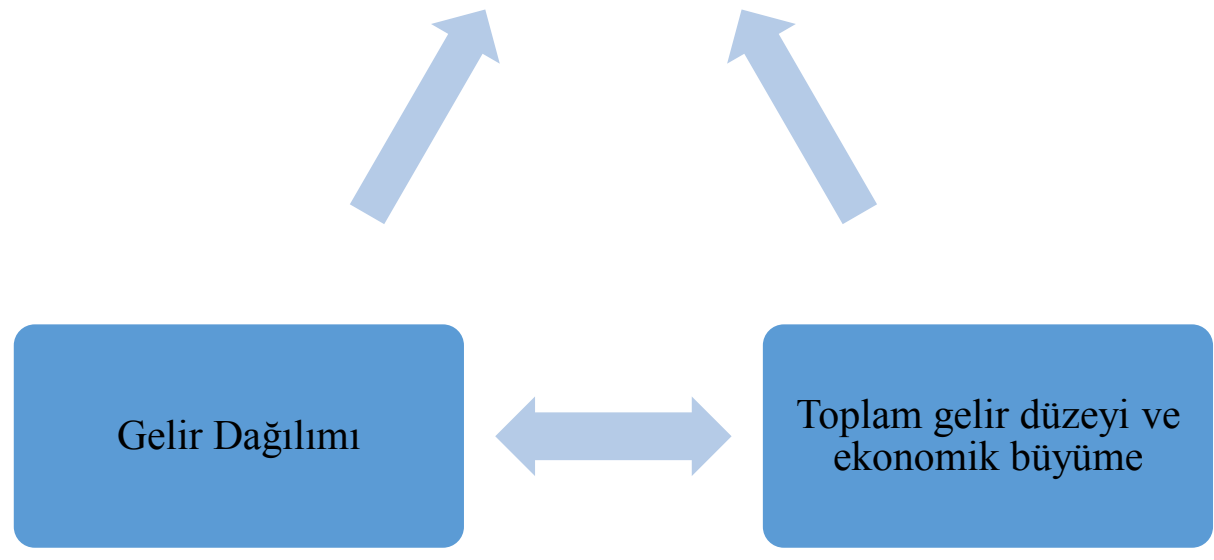

$\mathrm{Bu}$ çalışmanın amacı gelir dağılımı eşitsizliği ve yoksulluk sınırı serileri arasındaki ilişkiyi OECD ülkeleri ve AB üyesi ülkeler için analiz etmektir. Bunun için gelir dağılımı eşitsizliğini Gini katsayısı ile alarak ve göreceli yoksulluk sınırı ile arasındaki arasındaki ilişkiyi sabit-etki, rassal-etki ve havuzlanmış regresyon ile test ettikten sonra havuzlanmış regresyon modelinin en uygun model olduğuna karar verilmiştir. Çalışmanın ikinci bölümünde ilgili iktisat yazınından makalelere yer verilmektedir. Üçüncü ve sonraki bölümlerde ise veri seti, model ve modelin değerlendirilmesi üzerine yoğunlaşılmaktadır. 


\section{Literatür}

Gelir dağılımını kişisel ve fonksiyonel açıdan incelemek mümkündür. Gelirin yaratılmasına katkısı olan üretim faktörlerinden emek ve sermayenin gelirden aldıkları payları analiz eden yaklaşım fonksiyonel dağılımdır. Kişisel dağılımda ise, kişi veya aile gruplarına dağıtımı esas alınmaktadır. Bölgesel ve sektörel olmak üzere farklı gruplandırmalar da söz konusudur. Ekonomide gelir dağılımındaki eşitsizlik, mal talebi ve arzının dağılımın daha eşit olması durumundaki seviyenin altında olmasına neden olur (Karluk,2009, s.69).

Dağılımda eşitsizliği ölçmede kullanılan en popüler araçlar, Gini katsayısı ve Lorenz eğrisi ve bazı çalışmalarda Theil istatistiğidir (Taştan ve Akar,2013, s.22). Lorenz eğrisi bir dönemde ekonomide yaratılan reel gelirin yüzde olarak kişisel bölüşümünü gösteren eğridir. Bir karenin yatay ekseninde nüfus dilimleri birikimli ve yüzde olarak, dikey eksende ise kişilerin gelir dilimleri yine birikimli ve yüzde olarak gösterilir. Toplumda gelir yüzde yüz eşit olarak dağılıyorsa Lorenz eğrisi karenin köşelerini birleştiren bir doğru olacaktır. Eşitsizlik arttıkça Lorenz eğrisi eş bölüşüm doğrusundan (tam eşitlik doğrusu) uzaklaşarak daha yatık hale gelecektir. Gini katsayısı ise, eş bölüşüm doğrusundan ile Lorenz eğrisi arasında kalan alanın eş bölüşüm doğrusunun altında kalan üçgenin alanına oranıdır (Hyman,1983). Gelir dağılımı eşitsizliği arttıkça Lorenz eğrisi mutlak eşitlik doğrusundan uzaklaşır.Toplumda gelir dağılımı yüzde yüz eşit ise Gini katsayısı sıfır olur.

Şekil 2: Lorenz Eğrisi

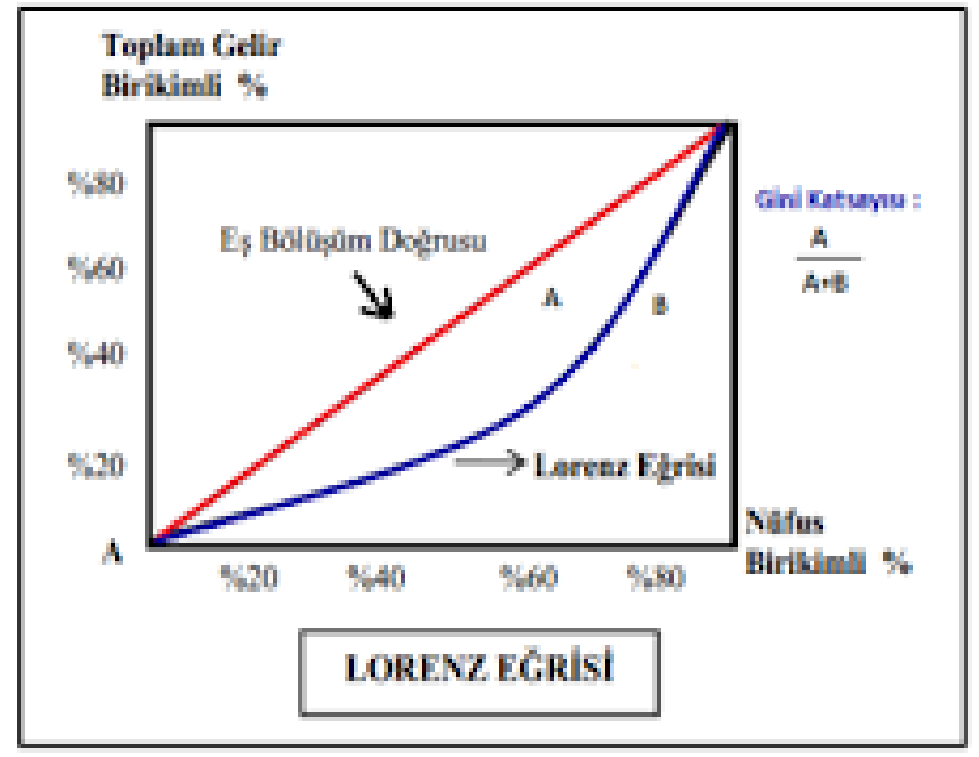

Bir ülkede gelir eşitsizliği, gelirin o ülkede eşit ve adil olarak bölüşülmediğinin en önemli kanıtlarındandır (Kuştepeli ve Halaç, 2004, s.144). Gelirin eşitsizliği, kaynakları paylaşanlar arasında kişisel huzursuzluklar doğurabilir ve toplumun genel huzur ve dengesinde de olumsuz etkiler oluşturabilir (Özdemir, 2017, s.75). Ekonomik büyümenin sağlanıp gelir elde edilmesi kadar gelirin paylaşılması önemlidir. Gelir dağılımını etkileyen farklı etkenler olabilir. Yoksulluk bunlardan biridir.

Farklı yoksulluk tanımları bulunmaktadır. TÜİK 2008 yılında Gıda ve Tarım Örgütü (FAO) ve Dünya Sağlık Örgütü (DSÖ) tarafından belirlenen yetişkin bir kişinin minimum harcaması gereken günlük kalori değerini (2.100 kalori) kullanmıştır (www.tüik.gov.tr). Bu yaklaşım, birçok ülkede hala uygulanabilmektedir. Hindistan'da asgari düzeyde beslenme, en temel yoksulluk eşiği olarak kullanılmaktadır (Şenses,2001). Mutlak yoksulluk sınırı gıda 
harcamalarına ek olarak temel gereksinimleri de (eğitim, sağlık, barınma, giyim) baz alarak hesaplanabilir. Günümüzde birçok az Gelişmiş Ülkelerde bu yaklaşım (Temel İhtiyaçlar Yaklaşımı) baz alınarak mutlak yoksulluk sınırı hesaplanmaktadır.

Yoksulluğun ölçülmesinde bir diğer sorun, farklı hane büyüklükleri için hesaplamanın nasıl olacağıdır. Farklı büyüklükteki hanelerin kıyaslanabilmesi için tüketim harcamalarında ayarlama yapılması gerekmektedir. Yoksulluğun ölçülebilmesi için hangi tüketim düzeyinin altında kalan henelerin yoksul sayılacağına karar verilmesi gerekmektedir. TÜİK raporlarında bütçe anketlerinin verileri kıstas alınırken Dünya Bankası raporlarında düşük gelirli ülkeler için günde 1 Amerikan dolarını mutlak yoksulluk sınırı olarak almaktadır. Bu oran Doğu Avrupa ve Orta Asya ülkeleri için 2,15 dolar ve 4,30 dolardır (WB-TÜİK,2005).

Yoksulluk, artan işsizlikle birlikte Avrupa Topluluğu'na üye ülkelerde 1970'li yılların ortalarından itibaren, önemli hale gelmiştir. Avrupa Topluluğu'na üye ülkelerde, işsizliğin, 1970'li yıllarda, büyümeye karşın çok yüksek oranlara ulaşması, nüfusun yaklaşık üçte birinin yoksulluk sınırına gerilemesine ve "üçte ikilik toplum" kavramının yaygınlaşmasına yol açmıştır. Yoksulluk, 1980'li ve 1990'lı yıllarda önemli bir artış göstererek Avrupa'nın "sosyal birlikteliğini" tehdit eden boyutlara ulaşmıştır (Room,1990, s.8 ve Oaxaca,1995, s.173'ten aktaran, Şenses,2001, s.18). Örneğin, 1980'li yıllarda Birleşik Krallık’ta nüfusun en zengin \% 20 'lik kesiminin ortalama geliri \% 40, en zengin \% 1'lik kesiminin geliri \% 75 oranında artarken en yoksul \% 20'lik kesimin geliri sabit kalmıştır.

Gelir dağılımındaki eşitsizlik arttıkça yoksulluk düzeyi de o kadar artmaktadır. Bu nedenle, gelir dağılımını belirleyen faktörler ele alınırken yoksulluğu etkileyen faktörler de düşünülmelidir (Aktan ve Vural, 2002). Uluslararası ticaret fakirliği azaltıp, istikrarlı bir gelir dağılımını sağlayacaktır. Ticaret hadleri etkisiyle ülkeler, farklı teknolojiler ile birlikte, farklı gelir seviyelerinde aynı değerde büyüyeceklerdir. Uluslararası ticaretin büyümeyi hızlandıracağı, bunun sonucu olarak yoksulluğun azalacağını ileri sürülmektedir(Acemoğlu ve Ventura, 2001). Argümanın bir diğer tarafı ise gelir dağılımındaki eşitsizliğin yoksul ülkelerde büyümeyi geciktirip, zengin ülkelerde büyümeyi teşvik ettiğini savunmaktadır. $\mathrm{Bu}$ durum gelir dağılımını eşitleme politikalarının yoksul ülkelerdeki büyümeyi teşvik edici gerekçelerle haklı gösterilebileceği anlamına gelmektedir. Zengin ülkeler için, aktif gelir dağılımı, eşitlikten yararlanma ve genel ekonomik büyümedeki azalma arasında bir değiş tokuş getiriyor gibi görünmektedir (Barro, 1999, s.32).

Adam Smith'in Göreli Yoksulluk tanımı, toplumun genel refah düzeyinin altında kalan ve sosyal açıdan dışlanmış olan gruplar göreli yoksullardır. Göreli yoksullar, birinci dereceden yoksul olmaktan çok ikinci derecede dar gelire sahip, asgari yaşam seviyesini yakalamış olsalar da ortalama refah seviyesinin altında olan insanlardır. Temel ihtiyaçlarını kısmen karşılamakla beraber, eğitim, sağlık, sosyal katılım yönünden yetersizlerdir. Yoksulluğu göreli bir kavram olarak yorumlayan ve sosyal yönü daha fazla olan göreli yaklaşım, yoksulluğu bireyin ihtiyaçlarını karşılama gücü yönüyle toplumun diğer bireyleri karşısındaki durumuna göre tanımlamaktadır.

Yoksulluk kavramı çok çeșitli açılardan incelenmiștir. Feldstein (1998) makalesinde ekonomide asıl sorunun gelir dağılımı eşitsizliği değil yoksulluk olduğunu belirtmiştir. Üç farklı yoksulluğun üç temel kaynağını belirleyerek yoksulluğu önlemede neler yapılabileceğini vurgulamıştır. Gupta, Davoodi ve Terme (2002) çalışmasında yoksulluk ve Gini katsayısının yolsuzluğa etkisini araştırmıştır. Buna göre yolsuzluğun standart sapmasında bir birimlik bir artış, Gini katsayısını 11 puan ve fakir kesimin gelir büyümesini \%5 oranında arttırmaktadır.Deininger ve Squire (1996) çalışmasında yoksulluk azalması ve büyüme arasında güçlü pozitif bir ilişki bulmuşlardır. Ravallion (2001) çalışmasında ülkeler arasında ekonomik büyümeyi paylaşan yoksul sayıları açısından büyük farklar olduğunu belirtmiştir. 
Bu nedenle büyüme ve gelirin dağılımındaki değişimi görebilmek açısından daha derin mikro analizlere ihtiyaç olduğunu vurgulamıştır.Fosu (2017) çalışmasında hem artan hem de azalan yoksulluğun belirlenmesinde büyümenin temel belirleyici olduğu sonucuna ulaşmıştır. Gelişmekte olan ülkelerde ekonomik, politik ve sosyal küreselleşme hem yoksulluğu hem de gelir eşitsizliğini azaltmaktadır (Yanar ve Şahbaz,2013). Yoksulluğun kadınsılaşması Türkiye'de yaşanan yoksulluğa dair olgulardan biridir (Dayığlu ve Kasnakoğlu,1997).

\section{Veri ve Model}

$\mathrm{Bu}$ çalışmada kullanılan doğrusal regresyon modelinin formu aşağıdaki eşitlikte görüldüğü gibidir. GP (gelir payları-incomeshareratio) olup TY (toplam yoksulluk eşiği oranı) değişkenidir. Veri seti 2007, 2012 ve 2014 olmak üzere 3 yıla ait yoksulluk, Gini katsayısı ve gelir payları serilerinden oluşmaktadır. Ülkeler 35 OECD ülkesi ile 26 adet AB üyesi ükeyi kapsamaktadır. Tablo 1, veri setinden bir kesiti göstermektedir. Aşağıda görülen model, logaritması alınmış Gini katsayısını bağımlı değişken olarak almakta, gelir payları (GP) ve toplam yoksulluk eşiğini (TY) bağımsız değişkenler olarak ele almaktadır.

$$
\text { Lgini }=\propto_{i t}+\boldsymbol{\beta}_{1} \boldsymbol{G} \boldsymbol{P}_{1 i t}+\boldsymbol{\beta}_{2} \boldsymbol{T} \boldsymbol{Y}_{2 i t}+\boldsymbol{\mu}_{\mathrm{it}}
$$

Panel veri analizinin bireyler, ülkeler veya firmalar ile ilgili heterojenliği kontrol etmede avantajlı olduğu bilinmektedir. Zaman serisi veya yatay kesit analizler heterojenliği kontrol etmede şüpheli sonuçlar elde etme riski taşımaktadır. Panel verinin bir diğer avantajı ise çoklu doğrusal bağlantının daha az olması, daha fazla serbestlik derecesi ve etkinliktir (Baltagi,2005, s.5).

Mundlak (1961) ve Wallace ve Hussain (1969) sabit etkiler modelini savunurken Balestra ve Nerlove (1966) rassal etkiler modelini savunmuştur. Hausman (1978) tarafindan geliştirilen Hausmanspesifikasyon testi bu modellerden hangisinin uygun olduğuna karar vermede kullanılmaktadır. Chamberlain (1984) sabit etkiler modelinin koymuş olduğu kısıtların geçerliliğinin kontrol edilmesi gerektiğini göstermiştir. Mundlak (1978)'a göre rassal etkiler modeli bütün tahmincilerin dişsal olduğunu varsaymaktadır. Aksine sabit etkiler modeli, içselliğe yer vermektedir. Bu nedenle tahmincilerin dışsallığ 1 seçimi bir "ya hep ya hiç" durumudur.

Tablo 1: Analize konu olan ülkelerden bir grubunun gelir dağılımı ve yoksulluk değişkenleri

\begin{tabular}{|c|c|c|c|c|}
\hline \multirow{3}{*}{ Ülke } & Yıl & Gini Katsayısı & $\begin{array}{c}\text { Gelir paylari } \\
\text { oranı }\end{array}$ & $\begin{array}{c}\text { Toplam yoksulluk } \\
\text { oranı (göreceli sınır) }\end{array}$ \\
\hline Avusturya & 2007 & 0.285 & 4.4 & 9.8 \\
\hline & 2012 & 0.276 & 4.3 & 9.6 \\
\cline { 2 - 5 } & 2014 & 0.280 & 4.2 & 10.0 \\
\cline { 2 - 5 } & 2014 & 0.268 & 4.0 & 5,9 \\
\hline Danimarka & 2007 & 0,244 & 3.4 & 5.4 \\
\hline \multirow{3}{*}{ Finlandiya } & 2012 & 0.249 & 3.5 & 5.4 \\
\hline & 2014 & 0.254 & 3.6 & 7.8 \\
\hline & 2007 & 0.269 & 3.9 & 6.8 \\
\cline { 2 - 5 } & 2012 & 0.262 & 3.8 & 9.0 \\
\hline Almanya & 2014 & 0.257 & 3.7 & 8.4 \\
\hline & 2007 & 0.285 & 4.3 & 9.0 \\
\cline { 2 - 5 } & 2012 & 0.289 & 4.3 & 13.3 \\
\hline Yunanistan & 2014 & 0.294 & 4.4 & 15.1 \\
\hline & 2007 & 0.33 & 5.6 & 15.1 \\
\hline & 2012 & 0.34 & 6.3 & 11.9 \\
\hline
\end{tabular}




\begin{tabular}{|c|c|c|c|c|}
\hline \multirow{3}{*}{ İspanya } & 2007 & 0.324 & 5.6 & 14.2 \\
\hline & 2012 & 0.335 & 6.1 & 14.0 \\
\cline { 2 - 5 } & 2014 & 0.346 & 6.7 & 15.9 \\
\hline Turkey & 2007 & 0.409 & 7.9 & 8,4 \\
\hline & 2012 & 0.402 & 7.8 & 9.0 \\
\cline { 2 - 5 } & 2014 & 0.393 & 7.6 & 8.8 \\
\hline İngiltere & 2007 & 0.373 & 6.6 & 9.7 \\
\hline
\end{tabular}

Kaynak:www.oecd.org/social/income-distribution-database.htm

Hausman testinin sonucu sabit ve rassal etkiler arasında bir seçimden ziyade hata terimleri ile açıklayıcı değişkenler arasında korelasyon olup olmadığını test etmek ile ilgilidir. Eğer $u_{i} v e x_{i}{ }^{\prime} l e r$ arasında korelasyon var ise bunlar sabit etkili olmayacaktır. Bunun yerine grup içi (withinestimator) tahminci kullanılacaktır (Erlat,2006, s.22). Tablo 2'de model-1, 35 OECD üyesi ülke ve model-2 26 AB üyesi ülkesinden oluşan iki grup olarak görülmektedir.

Tablo 2: Tanımlayıcı istatistikler

\begin{tabular}{|l|c|c|c|}
\hline Model 1 & & & \\
\hline Değişken & Gözlem & Ortalama & Std Sapma \\
\hline Lgini & 96 & -.494 & .127 \\
\hline GP & 105 & 5.442 & 3.875 \\
\hline TY & 94 & 11.207 & Std Sapma \\
\hline Model 2 & & & .0591 \\
\hline Değişken & Gözlem & Ortalama & 1.142 \\
\hline Lgini & 72 & -.527 & 3.067 \\
\hline GP & 78 & 4.791 & 10.026 \\
\hline TY & 72 & & \\
\hline
\end{tabular}

Sabit etkiler ve rassal etkiler modeli ayrı ayrı stata programında tahmin edilmiştir. Hangi modelin daha uygun olduğuna karar vermek için Hausman testi uygulanmıştır (Bkz. Tablo 3). Hausmantesti'ne göre rassal etkiler modeli daha uygun olarak ortaya çıkmıştır. Tablo 4'de rassal etkiler modeli sonuçları görülmektedir.

Tablo 3: Hausman Testi

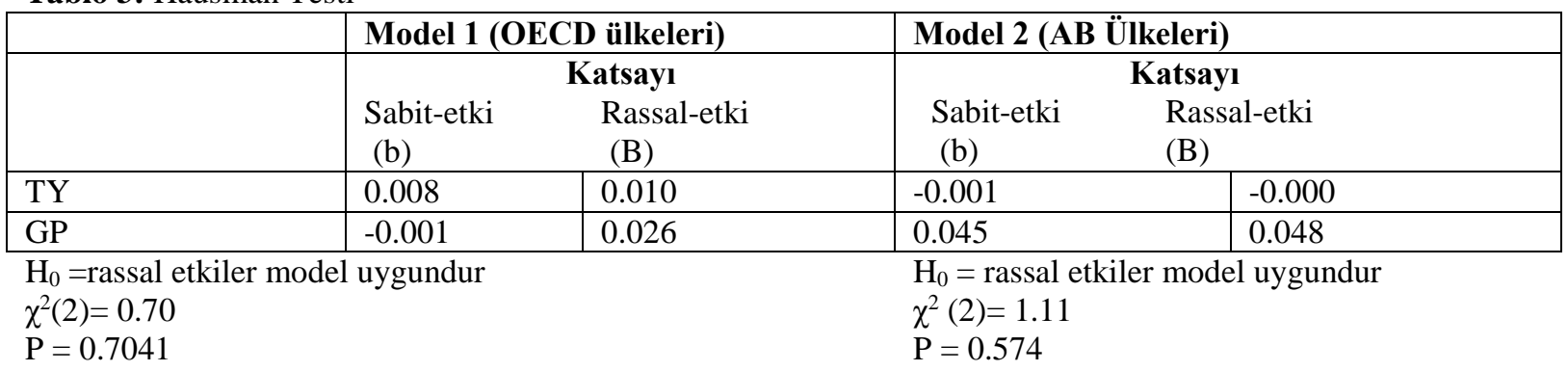

Hausman testi sonuçlarına göre "rassal etkiler modeli uygundur" diyen sıfır hipotezi kabul edilmiştir. Bu nedenle rassal etkiler modeli aşağıda görülmektedir. Hata terimlerinde değişen varyans olup olmadığını kontrol etmek amacıyla yapılan Breusch-Pagan testi, aynı zamanda rassal etkiler modelinin uygunluğunu kontrol etmek amaciyla kullanılmaktadır. Buna göre Breusch ve Pagan testinin sıfir hipotezi havuzlanmış regresyonun (pooled-ols) uygun olduğu varsayımına dayanmaktadır. Burada ki kare $\left(\chi^{2}\right)$ olasılık değeri 0.05 'ten büyük olduğu için sıfır hipotezi yani havuzlanmış regresyon uygun model olmaktadır.

Tablo 4: Rassal etkiler regresyon tahmin sonuçları

\begin{tabular}{|l|l|l|l|l|}
\hline \multicolumn{2}{|l|}{$\mid \begin{array}{l}\text { Model 1 (OECD ülkeleri) } \\
\end{array}$} & $\begin{array}{l}\text { Gözlem sayısı=93, } \mathrm{R}^{2}=0.40(\mathrm{se}) \\
\text { Grup }=35 \\
\text { Wald } \chi^{2}(2)=42.24 \mathrm{P}=0.000\end{array}$ & $\begin{array}{l}\text { Gözlem sayısı }=71, \mathrm{R}^{2}=0.91(\mathrm{se}) \\
\text { Grup }=26 \\
\text { Wald } \chi^{2}(2)=569.13 \mathrm{P}=0.000\end{array}$ \\
\hline $\begin{array}{l}\text { Bağımlı Değ. } \\
\text { (lgini) }\end{array}$ & Katsayı & Std.Hata & Katsayı & Std.Hata \\
\hline
\end{tabular}




\begin{tabular}{|l|l|l|l|l|}
\hline TY & 0.010 & $0.005^{* *}$ & -0.000 & 0.001 \\
\hline GP & 0.026 & $0.010^{*}$ & 0.048 & $0.002^{*}$ \\
\hline Sabit & -0.755 & $0.041^{*}$ & -0.763 & $0.010^{*}$ \\
\hline \multicolumn{5}{|l|}{} \\
\hline \multicolumn{5}{|l|}{} \\
\end{tabular}

*\%5 anlamlılık düzeyi

$* * \% 10$ anlamlılık düzeyi

Tablo 5'de göre, toplam yoksulluk, gelir payları değişkenleri ile Gini katsayısı arasında pozitif yönlü anlamlı bir ilişki vardır. Teori ile uyuşan bu durum, toplam yoksulluktaki artışın gelir dağılımı eşitsizliğinde artışa neden olduğu anlamına gelmektedir. Model 2'de AB ülkeleri içi regresyon sonuçları görülmektedir. Buna göre, sabit ve gelir payları anlamlı olup toplam yoksulluk anlamlı değildir.

Tablo 5: Havuzlanmıs regresyon (pooled-ols)

\begin{tabular}{|l|c|c|c|l|c|c|c|}
\hline Model 1 & \multicolumn{3}{l|}{ Model 2 } \\
\hline $\begin{array}{l}\text { Gözlem=93 } \\
\begin{array}{l}\mathrm{P}(2,90)=30,69 \\
\mathrm{P}>\mathrm{F}=0.000 \\
\mathrm{R}^{2}=0.405\end{array}\end{array}$ & $\begin{array}{l}\text { Kareler } \\
\text { toplamı }\end{array}$ & $\begin{array}{l}\text { Serbestlik } \\
\text { derecesi }\end{array}$ & $\begin{array}{l}\text { Ortalama } \\
\text { kareler }\end{array}$ & $\begin{array}{l}\text { Gözlem=71 } \\
\mathrm{F}(2,68)=502,40 \\
\mathrm{P}>\mathrm{F}=0.000 \\
\mathrm{R}^{2}=0.91\end{array}$ & $\begin{array}{l}\text { Kareler } \\
\text { toplamı }\end{array}$ & $\begin{array}{l}\text { Serbestlik } \\
\text { derecesi }\end{array}$ & $\begin{array}{l}\text { Ortalama } \\
\text { kareler }\end{array}$ \\
\hline Model & 0.613 & 2 & 0.306 & Model & 0.210 & 2 & 0.059 \\
\hline Hata & 0.899 & 90 & 0.009 & Hata & 0.018 & 68 & .0002 \\
\hline Toplam & 1.513 & 92 & 0.016 & Toplam & .2290 & 70 & .0032 \\
\hline Lgini & Katsayı & Std.Hata & P(Olas.) & Lgini & Katsayı & Std.Hata & P(Olas.) \\
\hline GP & 0.027 & 0.009 & $0.004^{*}$ & GP & 0.04 & .002 & $0.000^{*}$ \\
\hline TY & 0.009 & 0.004 & $0.031^{*}$ & TY & -0.0001 & 0.0008 & 0.872 \\
\hline Sabit & -7.755 & 0.034 & $0.000^{*}$ & Sabit & -7.765 & 0.007 & $0.000^{*}$ \\
\hline
\end{tabular}

*\%5 anlamlılık düzeyi

\section{Değerlendirme}

$\mathrm{Bu}$ çalışma, OECD ülkeleri ve AB'ne üye ülkeler için Gini katsayısı ile toplam yoksulluk sınırı arasındaki ilişkiyi analiz etmeyi amaçlamaktadır. Sabit etkiler, rassal etkiler modeli Hausman testi ile analiz edildiğinde rassal etkiler modelinin uygunluğuna karar verilmiştir. Breusch-Pagan testi ile rassal etkiler modelinden emin olmak için bakıldığında havuzlanmış regresyon (pooledols) modelinin en uygun model olduğuna karar verilmiştir. Buna göre, model 1 yani OECD ülkeleri için 2007,2012 ve 2014 y1lları için bütün değiş̧kenler anlamlı çıkmıştır. Model 2 yani AB ülkeler grubu için toplam yoksulluk hariç diğer değişkenler anlamlı çıkmıştır.

Çalışmanın bulgularına göre, gelir payları ile Gini katsayısı arasında pozitif yönlü anlamlı bir ilişki bulunmuştur. Toplam yoksulluk eşiği oranı ise OECD ülkeler grubu için pozitif anlamlı, AB ülkeleri grubu için anlamlı değildir. OECD ülkeleri için, toplam yoksulluk sınırındaki artış gelir dağılımı eşitsizliğini arttırmaktadır. Yoksulluğun esneklik katsayısındaki artış gelir dağılımı eşitsizliğini de arttırmaktadır. Bu bulgu Ravallion(1997), Bourguignon (2004) çalışmaları ile uyumludur. Ravallion (1997)'ye göre, başlangıç eşitsizlik düzeyi yükseldikçe yoksulluk oranı düşmektedir. Bourguignon(2004) çalışmasında eşitsizlik, yoksulluk ve büyüme ilişkisini ele almıştır. Bu çalışmanın paralel bulgusu ise yoksulluktaki artışın eşitsizliğin bir nedeni olarak çıkmış olmasıdır.

Politika önerisi olarak genellikle ekonomik büyüme ile kıyaslanan yoksulluk ve eşitsizlik değişkenleri bir de yoksulluk eşitsizlik ilişkisi ikili olarak ele alındığında yoksulluğun eşitsizliğin nedeni olduğu söylenebilir. Mikro düzeyde ülke karşılaştırmaları ileriki çalışmalar açısından incelenebilir. Buna bağlı olarak gelir dağglımı eşitsizliğini azaltmada yoksulluğu azaltıcı iktisat politikalarına ihtiyaç vardır. İktisadi kalkınmada gerek 
işgücü piyasaları gerekse yeni sanayileşme politikaları açısından yoksulluğun azaltılması önemli amaçlardan biri olarak yerini korumaktadır.

\section{Kaynaklar}

Acemoglu, D. \& Ventura, J. (2001). The world income distribution, NBER Working Paper, No: 8083

Aktan, Ç. C. \& Vural, İ. Y. (2002). Gelir dağılımında adalet(siz)lik ve gelir eşit(siz)liği: terminoloji, temel kavramlar ve ölçüm yöntemleri, Yoksullukla Mücadele Stratejileri, Coşkun Can Aktan (ed.), Hak-İş Konfederasyonu Yayınları, Ankara.

Balestra, P. \&Nerlove, M. (1966). Poolingcrosssectionand time series data in theestimation of a dynamic model: Thedemandfornaturalgas. Econometrica, 34, 585- 606.

Baltagi, B.H. (2005). Econometricanalysis of panel data, 3rdEd. Chichester: John Wiley.

Barro, R. J.(1999). Inequalityandgrowth in a panel of countries.Journal of EconomicGrowth, $5(1), 5-32$

Bourguignon, F. (2004). ThePoverty-Growth-Inequalitytriangle. IndianCouncilforResearch on International EconomicRelations, WorkingPaper no:125.

Bourguignon, F. (2003).Thegrowthelasticity of povertyreduction: Explainingheterogeneityacrosscountriesand time periods. in: T. Eicherand $S$. Turnovsky, eds. Inequalityandgrowth. TheoryandPolicyImplications. Cambridge: The MIT Press.

Breusch, T.S. \& Pagan, A. R. (1980). Thelagrangemultiplier test anditsapplicationsto model specification in econometrics. Review of EconomicStudies, 47, 239-253.

Chamberlain, G. (1984). Panel data in Z. Grillichesand M. Intrilligator (eds.): Handbook of Econometrics, 2. Amsterdam: North-Holland.

Dayığlu, M. \&Kasnakoğlu, Z. (1997). Kentsel kesimde kadın ve erkeklerin işgücüne katılımları ve kazanç farklılıkları. ODTÜ Geliştirme Dergisi,24.

Deininger, K.\&Squire,L. (1996). A new data set measuringincomeinequality",The World Bank EconomicReview, 10(3), 1 September 1996, Pages 565591,https://doi.org/10.1093/wber/10.3.565.

Dollar, D.\&Kraay, A. (2002). Growth is goodforthepoor.Journal of EconomicGrowth 7(3), 195-225.

Erlat, H. (2006). Panel data: A selectivesurvey, firstrevision, METU

Feldstein,M. (1998). Incomeinequalityandpoverty. NBER WP no.6770, (DOI): $10.3386 / \mathrm{w} 6770$.

Fosu, A. K. (2017). Growth, inequality, andpovertyreduction in developingcountries: Recent global evidence.Research in Economics, 71(20), 306-336.

Gupta, S., Davoodi, H., \&Alonso-Terme, R. (2002). Does corruption affect in come inequality and poverty?.Economics of Governance, 3(1), 23-45.

Hausman, J.A. (1978). Specificationtests in econometrics. Econometrica, 46, 1251-1271.

Hyman, D. N. (1983). Publicfinance, Chicago: TheDrydenPress.

Karluk, R.(2009). Cumhuriyet'in ilanından günümüze Türkiye ekonomisi'nde yapısal dönüşüm, Beta yayınları, 12. Baskı, İstanbul.

Kuştepeli, Y.\& Halaç, U. (2004). Türkiye'de genel gelir dağılımının analizi ve iyileştirilmesi. Dokuz Eylül Üniversitesi Sosyal Bilimler Enstitüsü Dergisi, 6(4), 143-160.

Mundlak, Y. (1978). On thepooling of time seriesandcross-section data. Econometrica,46, 6985. Also in Maddala (1993),2, 108-124.

Ravallion, M. (2001). Growth, Inequalityandpoverty: lookingbeyondaverages.World Development, 29(11),1803-1815.

Ravallion, M.(2002). Externalities in ruraldevelopment. EvidencefromChina,Mimeographed, The World Bank. 
Ravallion, M. (1997). Can high in equality developing countries escape absolute poverty. EconomicsLetters 56(1):51-57,DOI: 10.1016/S0165-1765(97)00117-1.

Şenses, F. (2001). Küreselleşmenin öteki yüzü:yoksulluk. İletişim yayınları 770, Araştırmaİnceleme Dizisi 121 ISBN-13: 978-975-470-950-6.

Taştan, H. \&Akar, M. (2013). Türkiye imalat sanayinde bölgesel ve sektörel ücret eşitsizliği.Iktisat Fakültesi Mecmuası, 63, 17-49.

Wallace, T.D. \&Hussain A. (1969). Theuse of errorcomponentsmodels in combiningcrosssectionand time-series data.Econometrica, 37, 55-72.

World Bank andtheStateInstitute of Statistics, Turkey (WB-TÜIK) (2005).TurkeyJointPovertyAssesment Report, Report No. 29619-TU, August 8.

www.oecd.org/social/income-distribution-database.htm

Yanar, R., \& Şahbaz, A. (2013). Gelişmekte olan ülkelerde küreselleşmenin yoksulluk ve gelir eşitsizliği üzerindeki etkileri. Eskişehir Osmangazi Üniversitesi İktisadi ve İdari Bilimler Dergisi, 8(3). 